\title{
LA POLÍTICA DE FORMACIÓN DE SOBRAL/CE: un trabajo de corresponsabilidad institucional
}

\author{
Ana Maria Gimenes Corrêa Calil \\ ana.calil@unitau.com.br \\ https://orcid.org/0000-0002-4578-0894 \\ Universidade de Taubaté (UNITAU) \\ Taubaté, Brasil \\ Marli Eliza Dalmazo Afonso de André \\ marli.andré@gmail.com \\ https://orcid.org/0000-0002-0942-4008 \\ Pontifícia Universidade de São Paulo (PUC-SP) \\ São Paulo, Brasil
}

Recibido: 13/12/2020 Aceptado: 01/02/2021

\begin{abstract}
Resumen
Se reporta la investigación sobre el proceso de implementación de la política de formación continua en Sobral/CE y la evaluación de las contribuciones de esta formación para el desarrollo profesional de los profesores principiantes. Se utilizaron la entrevista semiestructurada, el grupo de discusión, el análisis de documentos y el cuestionario. Como sujetos: en la Secretaría de Educación, la superintendente de educación y la coordinadora de valoración de la profesión docente; en la Escuela de Educación Continua, la directora, la coordinadora de formación y los profesores formadores; y los profesores principiantes que evaluaron la formación en el municipio. Los directores, coordinadores y profesores son corresponsables del aprendizaje de los alumnos. Los resultados apuntan al desarrollo profesional de todas las instancias implicadas en el proceso de formación continua.
\end{abstract}

Palabras clave: formación continua; profesores principiantes; desarrollo profesional.

\section{A POLÍTICA DE FORMAÇÃO DE SOBRAL/CE: um trabalho de corresponsabilidade institucional}

\section{Resumo}

Relata-se pesquisa sobre o processo de implementação da política de formação continuada em Sobral/CE e sobre a avaliação das contribuições dessa formação para o desenvolvimento profissional dos professores iniciantes. Foram utilizados entrevista semiestruturada, grupo focal, análise de documentos e questionário. Como sujeitos: na Secretaria de Educação, a superintendente educacional e a coordenadora de valorização do magistério; na Escola de Formação Permanente, a diretora, a coordenadora de formação e professores formadores; e, professores iniciantes que avaliaram a formação do município. Os diretores, coordenadores e professores corresponsabilizam-se pela aprendizagem dos alunos. Os resultados apontaram para o desenvolvimento profissional de todas as instâncias envolvidas no processo de formação continuada.

Palavras-chave: formação continuada; professores iniciantes; desenvolvimento profissional.

Revista Paradigma (Edición Especial - "Políticas, Programas e Práticas de formação de profesores"), Vol. XLI, marzo de $2021 /$ pi - pf 


\title{
THE SOBRAL/CE FORMATION POLICY: a work of institutional co-responsabilityAbstract
}

\begin{abstract}
This work analyses the process of implementation of the politics of continued formation in Sobral/CE, and evaluate its contributions to the professional development of beginner teachers. Used semi-structured interview, focal group, document analysis and questionnaires. The subjects were in the Education Secretary, the educational superintendent and the coordinator of mastership appreciation; in the School of Formation of teachers, the principal, the coordinator of formation and former teachers; and beginner teachers that evaluated the formation of the city. The principals, coordinators and teachers cocharge each other for the students learning. The results have pointed to the professional development of all instances involved in the process of continued formation.
\end{abstract}

Keywords: continued formation; beginner teachers; professional development.

\section{Introducción ${ }^{1}$}

Sobral é um município que vem, nas últimas duas décadas, despontando no cenário brasileiro por apresentar bons resultados no Ideb. O estudo de Gatti, Barreto e André (2011) que mapeou as políticas de apoio aos docentes destacou a experiência de Sobral/CE como um dos raros exemplos de política voltada ao professor iniciante no país. Esse fato despertou atenção, e procurou-se, então, conhecer melhor as ações que vinham sendo empreendidas naquele município e seus efeitos no desenvolvimento profissional dos docentes e na qualidade da aprendizagem dos alunos dos anos iniciais da educação básica.

Muitas informações sobre a educação no município de Sobral foram obtidas em documentos de premiações do INEP (2005, 2006, 2008a e 2008b), Cadernos do Cenpec (2011, 2012), em vídeos documentais da Organização para Cooperação e Desenvolvimento Econômico (OCDE) e do Instituto Airton Senna, e em relatórios como o de Vieira (2011) ou da Fundação Leman em parceria com o Itaú Cultural (2012). Em geral, esses documentos se basearam em índices ou indicadores públicos como Ideb, Prova Brasil, IDH (Índice de Desenvolvimento Humano) e ressaltaram o sucesso da educação. Além do processo de municipalização do Ensino Fundamental e das políticas de avaliação e monitoramento que precisam ser analisadas em profundidade, a formação continuada de professores iniciantes ou em exercício, de diretores e dos coordenadores pedagógicos merecem ser examinadas com cuidado, para que se possa

\footnotetext{
${ }^{1}$ Esse texto foi produzido antes do falecimento da Profa. Dra. Marli André, em 04 de janeiro de 2021. Em respeito e como forma de homenageá-la, a primeira autora decidiu por manter seu nome no presente artigo.
} 
entender suas implicações no desenvolvimento profissional desses agentes escolares e na aprendizagem dos alunos.

Portanto, problematizar o processo da formação continuada desenvolvido pelo município de Sobral, bem como trazer à tona a materialização de suas ações, é o foco deste trabalho.

\section{Formação de professores e desenvolvimento profissional}

Faz-se necessário colocar a formação de professores no centro dos debates, evidenciála, não como mais uma obrigação que os professores, já sobrecarregados, precisam realizar, mas como direito, como parte da profissionalização, como possibilidade de melhoria do processo de ensino e aprendizagem, tanto de professores quanto de alunos e equipe gestora. $\mathrm{O}$ campo de estudos da formação continuada de professores, como aponta André (2010), tem se mostrado atraente aos pesquisadores, haja vista a crescente produção científica sobre temas relacionados ao trabalho docente e à formação. "Queremos conhecer mais e melhor os professores e seu trabalho docente, porque temos a intenção de descobrir os caminhos mais efetivos para alcançar um ensino de qualidade, que se reverta numa aprendizagem significativa para os alunos" (André, 2010, p. 176).

Analisar a formação docente continuada, transversal ao processo de qualificação dos professores, possibilita enxergar a qualidade do trabalho nas salas de aulas e seus efeitos na aprendizagem dos alunos. Possibilita, inclusive, rever a formação inicial dos professores. São relevantes as pesquisas que conjugam a participação dos professores na melhoria da qualidade do ensino e da aprendizagem dos alunos, por trazerem à tona as concepções dos professores, articulando-as com suas práticas de ensino e com a aprendizagem da docência. A compreensão dos processos de formação do docente e seus efeitos na sala de aula é uma tendência das pesquisas, tal como salienta Cochran-Smith (2006), que incita o pesquisador a pensar em pesquisas êmicas, com o olhar "de dentro e por dentro" da profissão.

O momento atual demanda uma educação de qualidade. Evidentemente, os professores estão na "linha de fogo", são os primeiros a serem responsabilizados por ela. Entretanto, a formação continuada que lhes é apresentada, na maioria das vezes, não é eficaz ou não considera as necessidades reais do cotidiano da sala de aula ou da escola, nem da equipe gestora. Faz-se necessária, então, uma formação continuada com ações sistemáticas e planejadas, visando ao 
desenvolvimento profissional dos professores e à melhoria da qualidade das práticas pedagógicas (Canário, 2007). As ações intencionais, planejadas e assistidas provocarão mudanças no processo de ensino e, consequentemente, na qualidade da aprendizagem.

Se o objetivo da formação continuada é contribuir para o desenvolvimento profissional docente, há que se considerar ambos os lados da moeda, a pessoa e o profissional. Quanto ao profissional, que ele se desenvolva em condições temporais e espaciais (Marcelo, 1999; 2010; Day, 2001; Vaillant, 2009), e quanto ao professor, que ele, provocado externamente por uma formação de qualidade, impulsione a autoaprendizagem, a reflexão sobre a sua ação diária, como apregoam Vaillant e Marcelo (2012), mas que tenha também, ainda que o aprimoramento da prática seja importante, o despertar da sua consciência política, sobretudo para não perder de vista a justiça social, a igualdade de oportunidades aos alunos e o amor aos ideais da profissão.

Nesse sentido, Conchran-Smith (2003, p. 75) faz uma crítica às pesquisas que examinam as relações entre a qualificação dos professores e os resultados educacionais, por "[...] tornarem rotina presumir que questões de qualidade de ensino simbolizam amplamente a melhoria total da educação". Considerar os professores como problema ou solução da educação é cômodo e revela uma visão reducionista do quadro educacional. A autora afirma que há pelo menos três questões entrelaçadas nos debates sobre a qualidade da educação: “1) a qualidade do ensino faz diferença no aprendizado dos alunos e em suas vidas? 2) como nós definimos a qualidade de ensino? 3) como nós recrutamos e preparamos da melhor maneira professores qualificados?" (Cochran-Smith, 2003, p. 75).

Há que se pensar numa formação continuada que englobe todos os envolvidos no que se refere à educação na escola, desde o gestor até os funcionários e, além destes, as Secretarias de Educação. Integrar-se-ia, assim, uma perspectiva colaborativa de formação, que viesse a criar condições favoráveis ao trabalho coletivo, o que congregaria esforços conjuntos de todos os envolvidos em benefício de melhor qualidade do ensino. Davis et al. (2012) ressaltam que, se não houver apoio por parte das Secretarias (políticas de educação que criem ações colaborativas nas escolas), será muito difícil para o professor perceber que a formação resulta em benefício próprio e coletivo.

A formação é um elemento importante do desenvolvimento profissional, porém não é o único, pois salário, condições de trabalho, relações de poder e clima organizacional são igualmente importantes. O desenvolvimento profissional, na perspectiva de Day (2001, p. 20- 
21), “[...] envolve todas as experiências espontâneas de aprendizagem e as atividades conscientes planificadas, realizadas para benefício, directo ou indirecto do indivíduo, do grupo ou da escola e que contribuem para a qualidade da educação na sala de aula". Abrangente e complexa, a definição feita pelo autor revela todos os prismas passíveis de provocar mudanças no comportamento do professor, sejam elas de natureza cognitiva, sejam de natureza relacional ou emocional.

Imbernón (2010) parte da premissa de que o desenvolvimento profissional docente envolve o desenvolvimento pedagógico, cognitivo, teórico e a compreensão de si mesmo; antes, porém, está subordinado à situação profissional, que colabora para o desenvolvimento da sua carreira, ou o impede. O autor aponta aspectos que influenciam o desenvolvimento profissional, como o salário, o mercado de trabalho, o clima de trabalho nas escolas, a promoção na profissão, as estruturas hierárquicas, a carreira docente e a formação permanente realizada ao longo da vida profissional. Conclui que, embora a formação seja um elemento importante para o desenvolvimento profissional, “[...] não é o único e talvez não seja o decisivo” (Imbernón, 2010, p. 46), mas é preciso importar-se com o desenvolvimento profissional de todo o pessoal que trabalha em uma mesma instituição de ensino, para que sejam capazes de melhorar, tanto a situação de trabalho, quanto seu conhecimento profissional.

\section{A formação dos professores iniciantes}

Ao se considerar o tempo e o espaço de aprendizagem do professor, um nicho importante tem sido destacado - o dos professores iniciantes. Se ainda há preocupação com relação aos professores "experientes" que estão em exercício, preocupação maior se deve ter com os iniciantes. Segundo Ávalos (2012), não porque estes sejam fruto de formações iniciais frágeis ou duvidosas, mas por estarem num momento sui generis da carreira, um momento que provoca sentimentos, sensações e experiências típicas. Desse modo, a aprendizagem da docência apoiase na defendida por Mizukami et al. (2006, p. 12): “[...] aprender a ser professor, neste contexto, não é, portanto, tarefa que se conclua após estudos de um aparato de conteúdo e técnica de transmissão". A autora segue afirmando que "[...] é uma aprendizagem que deve se dar por meio de situações práticas que sejam efetivamente problemáticas, o que exige o desenvolvimento de uma prática reflexiva e competente". E reitera que a aprendizagem da docência “[...] exige ainda 
que, além dos conhecimentos, sejam trabalhadas atitudes, as quais são consideradas tão importantes quanto os conhecimentos".

Como destaca Ávalos (2012), deve haver interesse em reconhecer a importância desse período de inserção profissional e suas peculiaridades, no sentido de as políticas públicas apoiarem formalmente, como já acontecem em alguns países, como Chile, Austrália e Inglaterra, políticas e processos de indução por meio de programas que evidenciam efeitos sobre as condições de trabalho dos professores iniciantes, sobre seu bem-estar profissional, sobre o sentido da autoeficácia, bem como sobre a qualidade de sua prática e sua permanência nas escolas.

No Brasil, algumas iniciativas de formação pré-serviço têm-se mostrado eficazes (Gatti, Barreto, \& André, 2011), mas não como políticas de indução. Os professores recém-formados vão em busca de trabalho nas escolas, disputam vagas em concursos públicos e acabam ingressando, quer na rede pública, quer em escolas privadas, e entram em crise ao perceber que não dispõem de uma série de conhecimentos, competências e habilidades que lhes são exigidas na prática profissional.

Ao ingressar na escola, os professores iniciantes deparam uma complexidade enorme de fatores que envolvem o fazer da sala de aula, e se conscientizam de que a formação inicial não os preparou suficientemente. Difícil também é preparar os professores iniciantes selecionando o que precisam saber e ser capazes de fazer. Segundo Mizukami et al. (2002); Reali (2009); Darling-Hammond, Baratz-Snowden (2005), entre outros, não há um jeito certo ou único para se comportar, de maneira mais séria, menos risonha, mais simpática, mais reservada. Da mesma forma, há variações nas práticas que devem ser aprendidas pelos iniciantes. Esses autores se preocupam com a preparação inicial que os professores devem receber, para serem capazes de ensinar no início de suas carreiras, mas alertam que devem continuar aprendendo ao longo da carreira, seja com seus colegas mais experientes, seja em programas de formação.

\section{Metodologia da pesquisa}

A fim de analisar o processo de formação continuada implantado pela Secretaria Municipal de Educação de Sobral e suas ações junto à equipe gestora e aos professores da rede municipal, tanto os mais experientes quanto os iniciantes, foi necessário detalhar as práticas, conhecer seus diferentes atores e, sobretudo, ouvi-los. 
Para a pesquisa aqui relatada foi adotada a abordagem qualitativa, que investe na resposta ao "[...] desafio da compreensão dos aspectos formadores/formantes do humano, de suas relações e construções culturais, em suas dimensões grupais, comunitárias ou pessoais" e que propõe "[...] a não neutralidade, a integração contextual e a compreensão de significados nas dinâmicas histórico-relacionais" (Gatti; André, 2010, p. 30).

Inicialmente foram entrecruzadas as informações do estudo das Políticas Docentes no Brasil, as legislações federais, do Ceará e de Sobral, leituras e análises dos prêmios publicados pelo INEP e OCDE e seus respectivos sites, as informações sobre o IDEB do município, acrescidas das informações fornecidas pela Secretaria Municipal de Educação relacionadas ao plano de carreira, ações articuladas, salários e premiações.

Por se tratar de políticas de formação continuada, foi necessário focar em três locus diferentes, mas interdependentes, a fim de abranger o maior número possível de agentes envolvidos nesse processo. O primeiro foi a Secretaria Municipal de Educação, personalizada pela Superintendente Educacional e pela Coordenadora de Valorização do Magistério. O segundo foi a ESFAPEM (Escola de Formação de Professores), onde os dados foram colhidos com a diretora, com a coordenadora da Formação Continuada e com alguns professores formadores. Por último, a Vila Olímpica, espaço onde acontecem as formações, a fim de coletar dados junto aos professores iniciantes, em estágio probatório. Cabe ressaltar que esses dados remontam de 2014 e que os avanços da educação em Sobral tiveram continuidade. Atualmente, a ESFAPEM se chama ESFAPEGE por estender seu papel junto à formação dos gestores. As formações passaram a ter carga horária online e possuem novo formato.

Enseja-se com os dados desse artigo, anunciar o impulso que as ações do processo de formação continuada do município, nele apresentadas, proporcionaram aos movimentos posteriores. Para tanto, foram conjugados três tipos de instrumentos: questionário, entrevista e grupo focal.

Os questionários foram utilizados quando se tratava de um número maior de pessoas a serem abrangidas, caso dos formadores e dos professores iniciantes. Os agentes da Secretaria e da ESFAPEM foram entrevistados, e alguns professores iniciantes participaram de um grupo focal. Os questionários foram submetidos ao programa Sphinx, em que as questões fechadas geraram gráficos e as abertas contribuíram para identificar o que os professores iniciantes pensam sobre si, a profissão e o trabalho na rede municipal de Sobral. Os registros das 
entrevistas e do grupo focal foram submetidos a análise de conteúdo. $\mathrm{O}$ fato de as entrevistas terem sido realizadas com diferentes "atores" do trabalho de formação continuada, fez com que elas se complementassem e fosse possível perceber as congruências do processo de formação no município.

Retomados os objetivos, os dados coletados nos diferentes espaços que tratam da educação em Sobral foram subdivididos nas seguintes categorias: a formação continuada da equipe gestora, a formação continuada dos professores e a formação continuada dos professores iniciantes.

\section{O desenvolvimento educacional de Sobral}

Inicialmente é preciso descrever o contexto da educação em Sobral. Tendo adotado a mesma tendência política da Gestão por Resultados do governo estadual, a cidade de Sobral investiu profundamente na educação de suas crianças. A gestão estadual do período 2003-2006 iniciou a implantação da Gestão Pública por Resultados (GPR) em seu plano de governo, denominando-a “Ceará Cidadania, Crescimento com Inclusão Social”. Seu maior propósito era racionalizar os recursos públicos. O modelo de GPR adotado pelo Ceará baseou-se em experiências internacionais, incluindo o Canadá, e teve como pilares três etapas essenciais: Planejamento, Implementação e Monitoramento e avaliação.

Conforme depoimentos dos gestores da Secretaria de Educação, em 2000 foi realizada uma avaliação externa, a fim de mensurar o nível de aprendizagem das crianças. A avaliação constatou que $48 \%$ das crianças da $2^{\mathrm{a}}$ série não sabiam ler, e as demais séries também apresentavam um elevado grau de alunos não alfabetizados. O baixo indicador na alfabetização deflagrou o ponto de partida para uma política de governo que buscaria resultados. Foram planejadas e implantadas medidas que gerariam modificações no quadro flagrado. Algumas decisões foram tomadas, como a implantação do processo de municipalização e a reestruturação da rede, com as seguintes medidas: a) as creches que até então pertenciam à Secretaria do BemEstar Social passaram para a Secretaria de Educação; b) acordo com a Secretaria Estadual, que se responsabilizaria pelo Ensino Médio, enquanto o Ensino Fundamental ficaria a cargo do município, para atendimento a toda a matrícula pública de $1^{\mathrm{a}}$ a $5^{\mathrm{a}}$ série; c) blindagem das escolas, ou seja, não haveria interferência política para matrículas e transferências; d) amparo legal por meio de decretos para todas as medidas tomadas, a fim de garantir sua continuidade, por 
exemplo, gratificações, formação para os professores em estágio probatório; e) com a verba do Fundef (ainda não era o Fundeb), foi possível que a SEMED assumisse maior controle sobre as matrículas nas escolas, melhorasse a estrutura física das creches, bem como seu mobiliário; e, f) nucleação das escolas.

Sobral possui uma extensa área territorial, com distritos com até $70 \mathrm{~km}$ de distância. Administrar uma região tão grande e monitorar a qualidade da educação praticada nessas pequenas e longínquas salas de aula era muito difícil. As 98 escolas foram reduzidas a 39, no processo de nucleação, e a rede municipal de Sobral conta, atualmente, com 44 escolas.

Para o período de 2001-2004, a SEMED definiu estratégias de ação para implantar um diagnóstico com avaliação externa semestral da aprendizagem dos alunos e estabelecer metas de aprendizagem: Meta 1: Alfabetização na Idade Certa ( $1^{\mathrm{a}}$ e $2^{\mathrm{a}}$ séries -6 e 7 anos de idade); Meta 2: Alfabetização dos alunos de $3^{\mathrm{a}}$ a $5^{\mathrm{a}}$ séries (defasados e não defasados); Meta 3: Proficiência em Língua Portuguesa e Matemática (alunos já alfabetizados da $3^{\mathrm{a}}$ à $5^{\mathrm{a}}$ série) (Rossi, Silva, 2008, p. 4).

Além das metas estabelecidas, principalmente a de alfabetização de todos os alunos da rede, também foram criados três eixos estratégicos: a) Eixo de fortalecimento da gestão escolar (EFGE); b) Eixo de fortalecimento da ação pedagógica (EFAP); c) Eixo de valorização do magistério (EVM).

O Eixo de fortalecimento da gestão escolar (EFGE) tinha como sujeitos os diretores e os coordenadores escolares, e como objeto, a autonomia administrativa, pedagógica e financeira da escola.

O Eixo do fortalecimento da ação pedagógica teve como sujeitos os professores, e como objeto, a condução do trabalho em sala de aula. Para tanto, estabeleceu-se um conjunto de medidas de caráter pedagógico a serem tomadas, como exemplos: o estabelecimento de um programa de alfabetização que garantisse a alfabetização de 100\% das crianças com 6 e 7 anos de idade - Alfabetização na Idade Certa; garantia de proficiência em Língua Portuguesa e em Matemática, a todos os alunos da $3^{\mathrm{a}}$ à $5^{\mathrm{a}}$ que ainda não estivessem alfabetizados; atendimento a crianças de 6 anos incorporadas no Ensino Fundamental; implementação de apoio às práticas pedagógicas, oferecendo formação em exercício para os professores alfabetizadores; mudança na rotina estruturada em sala de aula; material didático para todos os alunos das salas de 
alfabetização; material de apoio pedagógico para alunos e professores; e, projetos escolares envolvendo a Literatura Infantil.

O Eixo de valorização do magistério teve como sujeitos os professores, e como objeto, a qualificação docente. Esse eixo visou: concursos públicos aos professores da rede, reajuste salarial, lançamento do Prêmio Escola Alfabetizadora/Prêmio Escola de Sucesso, Bônus para aquisição de computadores, incentivo salarial mensal diferenciado (a partir do resultado da aprendizagem da turma) e Programa de ampliação cultural - Olhares.

\section{A política de educação de Sobral}

O diagnóstico, a projeção e o alcance das metas foram questões que exigiram da política de educação do município de Sobral uma nova conceitualização e profunda reestruturação da rede, além de forte adaptação da equipe dos gestores e professores. Houve mudança do papel dos diretores, que assumiram o gerenciamento administrativo, financeiro e pedagógico da escola; necessidade de alfabetizar o grande número de alunos que estava no sistema escolar apresentando resultados sofríveis; exigência de olhar para os professores alfabetizadores; formação continuada para os professores e a introdução da cultura da avaliação e da premiação para os melhores resultados. Esse processo de reestruturação da rede alavancou todo o sistema educativo municipal de Sobral.

Foram necessários investimentos sobre a base de conhecimentos de alfabetização, tanto de professores quanto de gestores, e apoio terceirizado para essa formação do projeto PAIC Programa de Alfabetização na Idade Certa, que passou a ser um programa estadual e que, atualmente, tornou-se um programa federal. Seguindo as prospectivas, além $\operatorname{dos} 1^{\circ}$ e $2^{\circ}$ anos, a rede passou a exigir também melhor nível de aprendizagem para os alunos do $3^{\circ}$ ao $5^{\circ}$ ano, ampliando a formação continuada e a premiação para essas turmas.

A formação continuada também veio acompanhada pela modificação das práticas de sala de aula. Houve modificação na rotina e na didática do professor. Foi criada a ESFAPEM, que promove a valorização do docente na divulgação de experiências exitosas e encontros específicos para seu desenvolvimento cultural e profissional. Além disso, houve amadurecimento da equipe gestora, ações de formação continuada aos professores, formação continuada para os iniciantes articuladas a ações de premiação, avaliação municipal e 
acompanhamento par e passo de toda a rede. Essas ações refletiram positivamente nos resultados do Ideb, que ratificaram essa evolução.

\subsection{A formação continuada dos diretores}

Os diretores passaram por várias formações. A primeira delas foi realizada com os mesmos profissionais contratados pela Secretaria à época do concurso, um grupo de psicólogos e pedagogos que acompanharam o processo de seleção e o início dos trabalhos dos diretores, numa espécie de coaching com acompanhamento individual. Na época, a equipe selecionou o perfil mais adequado de cada diretor para cada escola e, além disso, acompanhou-o durante o início do seu trabalho. Em seguida, eles cursaram uma especialização em Gestão Escolar realizada pela Universidade do Vale do Acaraú (UVA).

À época da coleta de dados, os diretores estavam em formação com uma equipe do LICEU, uma vez por mês, por oito horas. O LICEU é uma consultoria que foi contratada após ter recebido o prêmio do INEP (de cem mil reais). Segundo a Superintendente, "Nós já temos uma política aqui e todo mundo já ganhou os seus computadores. A gente decidiu aproveitar esse dinheiro e fazer uma formação pros nossos diretores". A verba recebida foi revertida em formação.

Em 2001, após a nomeação, aos diretores foi dada autonomia, mas lhes seria cobrada a responsabilidade de gerir a qualidade do ensino oferecido em sua escola. A SEMED iria discutir problemas diretamente relacionados à aprendizagem dos alunos. Com essa medida, a SEMED diminuiu o contato com os professores e impôs aos diretores de escola a mediação dessa relação, além das demais atribuições. De acordo com a superintendente "Hoje nós estamos com onze anos e a gente tem essa política como sagrada - o diretor é o carro chefe, o diretor é o responsável pelos resultados dentro da escola".

A autonomia das decisões dos diretores em suas escolas, apontada na fala da Superintendente, indica que o trabalho da Superintendência é observar, controlar e cobrar os resultados dos diretores referentes às avaliações. Para tanto, são realizadas reuniões de estudo, apresentação e comparação dos resultados aferidos pelas avaliações externas (semestral), estaduais e federais, para realizar um diagnóstico de cada uma das escolas. Quando há resultado de avaliação externa, são realizadas reuniões por polo, para as quais são convocados diretores e coordenadores. São socializados os resultados dos distritos correspondentes àquele polo, como 
ponderações sobre o que foi bom e sobre o que foi ruim. A publicação dos resultados permite que eles vejam os números uns dos outros, comparem, analisem e estabeleçam novas metas.

$\mathrm{O}$ atendimento/monitoramento realizado pela superintendência não faz distinção entre escolas pequenas e grandes, de zona rural ou zona urbana. Todas as escolas têm de chegar a resultados positivos.

[...] assim desmitifica toda a construção de dizer que é mais fácil alfabetizar poucos do que muitos. Porque além de ser uma escola imensa, a maior escola de Sobral é a melhor do estado do Ceará. E foi a escola que mais alfabetizou alunos. [...] nós temos o mesmo olhar independente da escola, se é aqui vizinha da prefeitura como se é a 80 quilômetros de distância. Não faz diferença de uma criança aqui da sede pra uma criança do distrito [...] anexo de uma escola lá dentro dos matos. Você pode ter certeza que aquela criança lê igual a criança aqui da sede sem nenhuma discriminação. Tudo aqui é proporcional, tudo é em rede (Superintendente educacional).

A proposta da SEMED é atingir a excelência com equidade, sem distinção entre as escolas e seus contextos. Neste cenário, o diretor e o coordenador devem cobrar e dar suporte ao professor, ao diretor, apoiando-o em suas dificuldades, e ao coordenador, auxiliando-o no planejamento de ações didáticas ao longo do mês de trabalho. Há, portanto, um espírito de corresponsabilidade, e ninguém assume sozinho os resultados positivos ou negativos. Os resultados são de todos.

\subsection{A formação continuada dos Coordenadores}

Os coordenadores, assim como os diretores, passaram por um processo seletivo. O diretor tem autonomia para escolher, em uma lista de selecionados, aquele com quem vai trabalhar. Há escolas com até seis coordenadores. O número de coordenadores é calculado pelo número de matrículas, e a relação é de um coordenador para cada grupo de 250 alunos. Os coordenadores também tiveram formação externa. Atualmente têm formação com as coordenadoras de Educação Infantil e Ensino Fundamental da própria SEMED. Bimestralmente, a superintendente participa da reunião de coordenadores juntamente com as coordenadoras da SEMED. É função dos coordenadores acompanhar o planejamento dos professores, realizado 
quinzenalmente na escola, no período de aula (4 horas). É função dele, também, acompanhar execução de atividades em sala de aula.

No caso de Sobral, tanto diretores quanto coordenadores estão engajados em formação continuada, o que denota a preocupação da SEMED com o desenvolvimento profissional da equipe gestora. Isso significa, de acordo com Davis et al. (2012) fortalecimento e legitimação da escola como lócus de contínua e permanente formação. A ênfase no engajamento da equipe gestora com os professores pode promover coesão no grupo e atitude colaborativa, pois todos estão direcionados para o atendimento das mesmas metas e dos mesmos propósitos.

O coordenador assume quinzenalmente, com os professores, compromisso com o planejamento que é realizado na escola, no período de aula, durante quatro horas. No momento em que os professores estão sendo acompanhados pelo coordenador, suas salas de aula estão com os professores substitutos. As ações de formação são inseridas no planejamento quinzenal, observadas e, se preciso, alteradas ao longo do período. O planejamento tem papel essencial. Todos os professores de Educação Infantil e Ensino Fundamental de $1^{\mathrm{o}}$ ao $5^{\mathrm{o}}$ ano fazem seu planejamento na escola, quinzenalmente, durante o horário de trabalho, e é função do coordenador acompanhar essa atividade.

\subsection{Os professores formadores, seu papel e sua formação}

Os professores formadores não são funcionários exclusivos da ESFAPEM, pois conciliam as formações com outro trabalho, também na educação. Antes da criação da ESFAPEM havia formação no município, mas não era sistemática como atualmente. Assim, muitos professores formadores já contratados pela rede municipal ingressaram na Escola de Formação. É incumbência dos formadores preparar os encontros mensais de formação. Reúnemse em grupo para combinar a rotina do dia. Segundo os professores formadores, cada grupo de formadores, dos diferentes níveis, reúne-se pelo menos duas vezes para debater, escolher material, discutir dinâmicas, decidir a agenda, dividir as atribuições e responsabilidades do encontro. Essa programação é submetida à apreciação da coordenadora de segmento da ESFAPEM, para anuência ou eventuais ajustes.

Indagados sobre quem forma os formadores, a maioria dos professores respondeu que não há uma formação sistemática, nem pela Secretaria, nem pela ESFAPEM. Uma lacuna que 
encontramos ainda é uma formação para nós formadores, que procuramos suprir fazendo grupos de estudo, buscamos nos atualizar com a leitura de livros e participando de congressos e seminários (F 6).

É de autonomia do próprio formador e para isso temos participado de cursos, congressos, especializações, porém nada direcionado à prática de formadores, que tem se construído e socializado no dia a dia (F2).

Os depoimentos revelam a inquietude dos formadores quanto a buscar aprimoramento. Embora implícita, essa é uma condição para que permaneçam como formadores na ESFAPEM. Por estarem tão próximos dos professores da rede, naturalmente têm opiniões sobre eles:

Hoje percebemos maior empenho dos professores em relação a tempos atrás. São capazes de realizar suas aulas de forma mais prazerosa tanto para si próprios quanto para os alunos. Em muitos casos percebemos professores autônomos, capazes de solucionar situações diárias da sala de aula, tendo como referência seus conhecimentos teóricos respaldados na prática $(\mathrm{F} 8)$.

Os professores da rede municipal de Sobral são, antes de tudo, guerreiros. São profissionais que colaboram com o sistema apesar das limitações da formação inicial, das dificuldades em conciliar atividades em mais de uma escola, apropriar-se de programas novos que exigem prática específica, estudo direcionado...Em minha opinião, esses professores, na maioria mulheres, avançaram muito em sua formação, pois reconhece no estudo a possibilidade de melhorar a vida. Nossos professores são movidos pela simplicidade. Apesar da formação acadêmica, têm um currículo baseado, sobretudo, na experiência do "dar aulas" e vivem momentos de transformações quase palpáveis (F 2).

Algumas fragilidades são apontadas no trabalho da formação dos professores.

Vejo que já percorremos um caminho, crescemos todos, aprendemos juntos conseguimos sair do nível crítico em que se encontrava a educação do município, mas, vejo, também, que ainda temos muito a aprender, precisamos qualificar a educação, precisamos trabalhar melhor a inclusão, precisamos de uma formação para os formadores, pois os professores estão se qualificando e nós precisamos também nos qualificar. (F 6)

Percebeu-se, ao longo da coleta de dados na ESFAPEM, preocupação premente com a didática em sala de aula. Não obstante, a busca pelos resultados nas avaliações não acontece isoladamente; ao contrário, os professores estão amparados pela formação em exercício, são apresentados a conteúdos e procedimentos que os ajudarão na condução da sala de aula. O investimento maciço e cuidadoso na formação dos professores tem refletido nos resultados dos alunos nas diferentes avaliações. 


\subsection{A formação continuada dos professores}

Todos os professores da rede municipal de Sobral frequentam a formação em serviço. Houve um processo de amadurecimento nos modelos de formação continuada executados pela SEMED que, em 1997 e 1998, era baseada em palestras e realizada pelos coordenadores da SEMED (Educação Infantil, Ensino Fundamental e EJA) e seus colaboradores.

A Superintendência, criada em 2001, ficou encarregada da formação dos diretores que, com autonomia, requeriam um novo perfil de professores. Nesse mesmo ano, após os resultados da avaliação diagnóstica dos alunos, a formação passou a focalizar a alfabetização das crianças de seis a oito anos $-1^{\circ} .2^{\circ}$ e $3^{\circ}$ anos. Quanto aos professores alfabetizadores, além de se adaptarem ao momento da exigência do maior número possível de alunos alfabetizados, passaram a participar da formação continuada que acontecia aos sábados e começaram a receber uma gratificação pelos resultados de seus alunos nas avaliações externas.

Em 2004, as formações foram estendidas para as demais séries, assim como as avaliações semestrais. Consequentemente, os demais professores - do $3^{\circ}$ ao $5^{\circ}$ ano - iniciaram um processo de formação continuada mais sistematizado, o que aconteceu também com a Educação Infantil. Ao mesmo tempo em que as ações de formação continuada eram realizadas pela equipe de coordenadores da SEMED, foram surgindo ideias de criar uma equipe que pensasse exclusivamente na formação continuada.

Quando da criação da ESFAPEM, em 2006, foi definida uma estrutura que contemplasse a ideia de formação em serviço. Essa estrutura, que fazia parte da política de valorização do magistério, deveria cumprir dois objetivos principais: a qualificação dos processos de ensino e a formação pessoal dos professores. A dimensão da qualificação do ensino, denominada fazer pedagógico, era composta pelas seguintes etapas: programa de ensino (chamado, posteriormente, de proposta curricular), a rotina de sala de aula e o material estruturado. Em relação à dimensão da formação pessoal, foi criado o Programa Olhares. Como afirma Oliveira (2009), essas duas dimensões - fazer pedagógico e formação pessoal -constituíram o centro das discussões. O fazer pedagógico era a necessidade mais premente da rede municipal de ensino.

A Formação em serviço dos professores da Rede Municipal de Sobral contempla todos os níveis de ensino, com uma carga horária de 8 horas mensais. A formação é presencial e a Escola de Formação acompanha, juntamente com diretores das escolas, a frequência dos professores nos encontros. O professor começa a participar da formação em serviço a partir do 
primeiro mês em que ingressa na rede municipal de ensino. Os encontros ocorrem separadamente para cada nível de ensino. A formação em serviço é centrada em uma orientação didática para preparar o professor para sua atuação na sala de aula.

De acordo com a equipe técnica da Secretaria de Educação, os professores têm oportunidade de aprender novas estratégias de ensino, enquanto estudam os temas abordados na formação que os prepara para desenvolver um trabalho mais eficiente em suas aulas.

A formação para a Educação Infantil - O encontro propriamente dito, com duração de oito horas/aula, acontece na Vila Olímpica. É realizada em dias diferentes para cada série. A Educação Infantil é composta por Infantil Bebê, Infantil II, III, IV e V. Como a formação é realizada em dias diferentes para cada série, há formadores que trabalham com professores do Infantil Bebê e Infantil V, por exemplo. Para toda a Educação Infantil a proposta da rotina da formação é a mesma, respeitando os eixos Acolhida, Relembrando, Texto de estudo, Conhecendo o nosso material, Orientações didáticas, Troca de Experiências, Registrando o que aprendi, e o momento do Cuidando do Mestre. Ao longo do período da tarde, são trabalhadas as Atividades Interdimensionais: Artes, Movimento, Música e Contação de Histórias. Todas elas são ministradas por formadores específicos das áreas. Mesmo assim, o formador titular acompanha as atividades juntamente com o seu grupo. Todas as propostas didáticas são vivenciadas durante a formação.

A formação para Séries Iniciais do Ensino Fundamental está estruturada da seguinte maneira: para a disciplina de Língua Portuguesa, no primeiro ano, é destinado todo o período da manhã. O período da tarde fica dividido entre Matemática, Ciências e Cuidando do Mestre. Nas séries seguintes, amplia-se o tempo da Matemática e das Ciências, diminuindo um pouco a carga horária destinada à Língua Portuguesa. Em todas as séries também acontece o Cuidando do Mestre. Cada série teve um dia específico de formação, ou seja, num dia estão reunidos todos os professores do $1^{\circ}$ ano, incluindo os iniciantes, o que lhes permite trocar opiniões e dúvidas com os demais colegas.

A formação para Séries Finais do Ensino Fundamental é mais recente que as demais formações, e também apresenta outro formato. Foi implantada em 2012. Não é realizada por todos os professores, mas por um professor orientador que viverá a formação e a transmitirá para seus pares da mesma área. Dessa forma, vem para a Formação um professor representante de cada escola. Para os professores de Português e Inglês, a formação tem duração de quatro 
horas (duas horas para cada disciplina). O mesmo acontece para os professores Matemática e Ciências e para os de História e Geografia.

A formação continuada para os professores iniciantes - Embora a atenção às necessidades dos iniciantes venha crescendo nos últimos anos, as experiências efetivas com a sua formação ainda são incipientes no Brasil. A política de Sobral é um dos poucos exemplos de formação pensada, executada e regulamentada para os ingressantes.

A discussão sobre a formação para os iniciantes teve início em meados dos anos 2000, quando se iniciaram também discussões sobre o plano de carreira e se percebeu que era preciso dar suporte e apoio ao professor que estava ingressando. Naquele ano foi implantado o Conselho Municipal de Educação. Contribuiu para a proposta o ingresso de professores no concurso de 2005 e a constatação de lacunas em sua formação. A partir de discussões e da necessidade de eliminar aquelas lacunas, surgiu a ideia de um programa de formação que atendesse aos professores que estavam iniciando sua experiência docente. De acordo com as entrevistadas, a iniciativa pretendia capacitar adequadamente os professores iniciantes, a fim de que atendessem à demanda do município e, ao mesmo tempo, se aproximassem da realidade educacional.

A participação na formação durante o estágio probatório é compulsória. Os professores recebem um incentivo financeiro de $25 \%$ do salário base de 4 horas. O investimento é incluído na folha de pagamento dos professores logo após o início da formação. Essa modalidade de formação compreende uma carga horária de 200 horas/aula, com frequência mínima de 80\% da carga horária. Passou a vigorar a partir do concurso de 2007, e os professores que ingressaram por concurso naquele ano realizaram o curso de formação em 2008 e 2009.

A diretora da ESFAPEM relata que algumas mudanças foram percebidas ao longo do ano em que os iniciantes frequentaram o curso de formação:

Com a formação do estágio probatório o que eu venho percebendo é como está sendo interessante para a construção da relação do coletivo da escola, sabe? A construção da relação do professor com o diretor, com o coordenador pedagógico no momento em que eles precisam estar ali, estudando toda a escola. [...] Então a gente viu o quanto isso está sendo importante para a própria escola como instituição e para o professor sentir o espaço escolar como um espaço em construção para a formação dele (DIRETORA DA ESFAPEM).

Os professores iniciantes frequentam simultaneamente dois programas de formação: um específico para ingressantes na rede - este do estágio probatório - e outro de formação continuada junto com outros professores da rede que trabalham as mesmas séries ou áreas. Dessa 
forma, entram em contato com duas formações que, embora distintas, são complementares. Segundo a diretora da ESFAPEM:

O estágio probatório é para o professor sentir o espaço escolar como espaço de construção pra formação dele. E a formação em serviço já tem outra estrutura que é a competência e o ofício do magistério, a competência pedagógica no sentido da eficiência do trabalho em sala de aula. A formação em serviço é voltada pra o que acontece dentro da sala de aula.

A oportunidade de poder frequentar ambas as formações fazem com que os professores iniciantes se sintam mais amparados. Possibilita-lhes uma visão global da escola e outra mais centrada na sala de aula, quando estão na formação mensal.

\subsubsection{Como os professores iniciantes veem a formação no Estágio Probatório}

Os dados dos professores iniciantes são provenientes do questionário respondido voluntariamente e de um grupo de discussão com oito integrantes que encerravam o curso de formação. Dos 36 professores, 10 apontaram como maior desafio no início de sua carreira a “discrepância entre o saber universitário e o fazer pedagógico" ou a "a falta de conexão entre a formação acadêmica (inicial) e a prática na sala de aula", fazendo uma alusão à formação inicial desconectada da prática. A formação didático-pedagógica precária fica mais acentuada quando esse professor assume a docência e se vê despreparado para as demandas da sala de aula:

Eu nunca tinha trabalhado na escola e aí tinha aquelas minhas dúvidas, questionamentos, não sei se estou agindo correto. Aí veio o estágio probatório. Pensei, ah então eles vão me dar, vão me nortear, vão me ajudar. Com certeza vai falar de Didática, vão falar de muita coisa boa, mas ficaram ainda aquelas dúvidas porque quando você sai da graduação, você não sai... a prática, o trabalho ainda vai me ensinar muito. A faculdade deixa a desejar. E aí o estágio probatório iria vir me direcionar melhor e ainda não terminou isso. (P5)

A fala da professora é bastante representativa, pois revela o medo e a insegurança impostos pela novidade da profissão. O fato de não possuir experiência docente faz emergir sua fragilidade didática e muitas questões relacionadas à sala de aula e à metodologia, características dos iniciantes.

Com relação aos desafios enfrentados no início da carreira, nove professores apontaram a falta de experiência em sala de aula, na escola pública, no exercício da profissão. O depoimento fornecido por uma professora iniciante revela bem essa insegurança: "Eu fiquei pensando: poxa, a gente, às vezes, se sente tão só. Acha que o problema é só da gente. Como ela falou, eu me 
sinto com medo. Eu não sei se estou acertando ou errando" (P 7). Sobre a formação no estágio probatório, vejam-se as falas que seguem:

[...] sobre esse estágio... tem sido totalmente novo pra mim por nunca ter feito concurso antes. E também a gente não esperava que tivesse esse curso de formação nesse formato. Creio que seja novo pra maioria aqui. Mas, por ser recente, por estar recente na área, ensinando há pouco tempo, por ser jovem ainda, eu tenho visto como muito importante, como muito valioso. (P1)

E pra mim foi uma experiência bastante rica porque, além das aulas proporcionadas pelos professores, algo que eu considero que me fez crescer muito também foi a própria troca de experiência. Já que estamos num grupo de professores, todos que estão aqui são professores, alguns mais recentemente outros há mais tempo. Esse intercâmbio de experiência, pra mim, foi muito rico além da própria... das aulas dos professores. Pra mim foi muito interessante! (P2)

Outro benefício do processo do estágio probatório, ele motiva você a estudar. Quem de nós aqui estaria toda terça-feira estudando sozinhos na nossa casa? Ou aplicando projetos? Então, o estágio probatório nos motiva a estudar. E ainda que ele não nos traga todo o embasamento que foi comentado, mas ele te instiga a ir atrás. Essa realização de projetos. Eu, por exemplo, não tinha costume, não tinha o hábito de desenvolver projetos. Então, no estágio probatório, eu vou ter que desenvolver quatro. Então, de alguma forma vai haver um crescimento pessoal e profissional. (P7)

Também expressaram suas críticas ao curso:

Poderia fazer uma crítica né, pode ser construtiva, é isso mesmo que a $\mathrm{M}$. também falou. É a falta de aprofundamento nas coisas. A gente viu nos módulos aquelas questões, didática, tudo, mas não foi muito aprofundado e não tirou todos aqueles... nós. É... com relação à troca é muito prazeroso, mas quando você se questiona e quando não vem uma resposta... isso nós aprendemos com as nossas experiências. A que nome se dá isso né? Saber da experiência... (P6)

Apontam como fatores para a melhoria do seu trabalho: melhoria do salário; redução do número de alunos por sala; melhor formação e maior apoio técnico; dedicação exclusiva. Como motivos que os fazem permanecer na rede municipal assim se expressaram: "não apenas pela remuneração, mas a preocupação e o acompanhamento do município, tanto nas formações como na aprendizagem dos alunos"; "acreditar no processo de qualificação na educação do município como um todo, na política educacional que gere a rede municipal". Elogiaram o "compromisso do gestor municipal em disponibilizar o que há de melhor para a educação das crianças”. Um deles disse que se sente valorizado: "gosto também quando sou valorizada pelo sistema 
municipal". Outros ainda acrescentaram: "o que estimula é a forma como a Secretaria da Educação acompanha as escolas, dando autonomia e, ao mesmo tempo, acompanhando o trabalho realizado por cada escola"; "o orgulho e o compromisso para com a educação de Sobral, que vem sendo destaque nacional”; “a forma responsável da gestão e também a 'camisa' que os

professores vestem. Todos querem uma escola "aprendente": "os avanços alcançados pela rede municipal e, principalmente, a participação nesses avanços”. Os professores indicaram alguns pontos sobre os quais ainda sentem falta na sua formação: continuidade dos estudos (pósgraduação, mestrado), falta de tempo para estudar e falta de valorização profissional.

\section{Considerações finais}

Ao longo da pesquisa descortinaram-se as ações que se articularam para a formação de um sistema educacional na rede municipal, que adota a meritocracia e a política de resultados como referência para a premiação das escolas e suas equipes. A saída encontrada pelo município para a condução dos trabalhos envolvidos na educação não está aqui apresentada como perfeita, mas, a seu modo, em suas circunstâncias, tem sido destacada por conseguir bons resultados.

A modificação na condução da rede municipal de ensino teve como ações disparadoras do processo: a vontade política, que cuidou de desencadear o processo de reestruturação da rede; a municipalização; a "blindagem" da escola aos interesses politiqueiros; a valorização da escola, com ataque atacando veemente ao problema da evasão escolar; proposta de realização de avaliação externa municipal, a fim de diagnosticar a competência do ensino e da aprendizagem dos alunos da rede; criação de um Plano de Carreira; e, regulamentação de todas as ações realizadas em forma de documentos (Decretos, Leis, Regulamento). A continuidade política foi fator importante para o fortalecimento das ações empreendidas.

Houve corresponsabilidade de todos os envolvidos, nos resultados das avaliações. Os diretores, os coordenadores, os professores, os formadores da ESFAPEM e a superintendente assumem juntos todos os resultados, realinham suas escolhas e seus planejamentos, quando necessário, de modo a atingir os resultados na aprendizagem dos alunos por meio das avaliações. A gratificação para os professores é baseada na média municipal dos resultados dos alunos, mas não é vista, pelo menos pelos professores iniciantes, como perniciosa.

A formação continuada assume grande importância, a ponto de ter sido criada uma Escola de Formação Permanente: todos os envolvidos: diretores, coordenadores e professores 
passam por formação em exercício. Essa é uma das formas de valorização do professor, que não está desatendido. Na escola, ele conta com o apoio do coordenador pedagógico, e na formação, com o apoio do formador. Dele são cobrados os resultados dos seus alunos, mas há respaldo da formação que cuida do ciclo profissional dos professores, promovendo formação específica para os professores iniciantes na rede, ao longo do estágio probatório, e para todos os professores em exercício. Há atendimento à formação cultural dos profissionais pelo Programa Olhares, o que aponta para o respeito à pessoa do profissional em seu processo de humanização.

\section{Referências}

ANDRÉ, Marli E.D.A. (2010). Formação de professores: a constituição de um campo de estudos. Educação. Porto Alegre, 33(3), 174-181.

ÁVALOS, Beatrice. (2012). Hacia la configuración de políticas de inducción para professores principiantes. In: III Congreso Internacional sobre Profesorado Principiante e Inserción Profesional a la Docência. Chile.

CANÁRIO, Rui. (2007). Formação e desenvolvimento profissional dos professores. In: Conferência Desenvolvimento Profissional de Professores para a Qualidade e para a Equidade da Aprendizagem ao longo da Vida. Lisboa.

Centro de Estudos e Pesquisas em Educação, Cultura e Ação Comunitária (2011). Os municípios e a qualidade das escolas na segunda etapa do ensino fundamental: as regularidades e as exceções do desempenho no IDEB. Informe de Pesquisa, n. 01. São Paulo: Centro de Estudos e Pesquisas em Educação, Cultura e Ação Comunitária (CENPEC).

COCHRAN-SMITH, Marilyn. (2003). Teaching quality matters. Journal of Teacher Education, $54(2)$.

Teacher Education, 57( 1).

. (2006). Taking Stock in 2006: evidence, evidence everywhere. Journal of

DARLING-HAMMOND, Linda \& BARATZ-SNOWDEN, Joan. (Eds.) (2005) A good teacher in every classroom: preparing the highly qualified teachers our children deserve. The National Academy of Education, Committee on Teacher Education, San Francisco.

DAVIS, Cláudia L. F. et al. (2012). Formação continuada de professores: uma análise das modalidades e das práticas em estados e municípios brasileiros. São Paulo: FCC/DPE.

DAY, Christopher (2001). Desenvolvimento profissional de professores: os desafios da aprendizagem permanente. Porto: Porto Editora.

Fundação Lemann; ITAÚ BBA. Excelência com equidade: as lições das escolas brasileiras que oferecem educação de qualidade a alunos de baixo nível socioeconômico. Recuperado de: http://www.fundacaolemann.org.br/uploads/arquivos/excelencia_com_equidade.pdf.

GARCIA, Carlos Marcelo. (2010). O professor iniciante, a prática pedagógica e o sentido da experiência. In: Formação Docente. 3(3),11-49. 
GATTI, Bernardete. A. \& ANDRÉ, Marli E.D.A. (2010). A relevância dos métodos de pesquisa qualitativa em Educação no Brasil. In: WELLER, V.; PFAFF, N. Metodologia da pesquisa qualitativa em educação: teoria e prática. Petrópolis: Editora Vozes.

GATTI, Bernardete. A.; BARRETO, Elba S. S. \& ANDRÉ, Marli E.D.A. (2011). Politicas docentes no Brasil: um estado da arte. Brasília: UNESCO.

IMBERNÓN, Francisco. (2010). Formação continuada de professores. Porto Alegre: Artmed.

Instituto Nacional de Estudos e Pesquisas Educacionais. (2005). Vencendo o desafio da aprendizagem nas séries iniciais: a experiência de Sobral/CE. Brasília: Instituto Nacional de Estudos e Pesquisas Educacionais Anísio Teixeira, 2005. Recuperado de www.inep.gov.br.

Instituto Nacional de Estudos e Pesquisas Educacionais. (2016). A política de alfabetização como estratégia para a elevação do desempenho escolar nas séries iniciais do Ensino Fundamental. Prêmio Inovação na Gestão Educacional 2006. Brasília: Instituto Nacional de Estudos e Pesquisas Educacionais Anísio Teixeira.

Instituto Nacional de Estudos e Pesquisas Educacionais. (2008). Fortalecimento da Gestão Escolar: seleção por critérios meritocráticos e formação continuada de diretores. Prêmio Inovação em Gestão Educacional, 2008. Brasília: Instituto Nacional de Estudos e Pesquisas Educacionais Anísio Teixeira.

MARCELO GARCIA, Carlos. (1999). Formação de professores. Para uma mudança educativa. Porto: Porto Editora.

MARCELO, Carlos. (2011, marzo). Políticas de inserción en la docencia: de establón perdido a puente para el desarrollo profesional docente. PREAL, (52).

MIZUKAMI, Maria da Graça Nicoletti \& REALI, Aline Maria de Medeiros (orgs.). Aprendizagem Profissional da Docência: Saberes, Contextos e Práticas. São Carlos, SP: EdUFSCar, 2002, p. 119 - 137.

MIZUKAMI, Maria da Graça N. et al. Formação de Professores: concepções e problemática atual. In: MIZUKAMI, M.G.N. et. al. Escola e aprendizagem da docência: processos de investigação e formação. São Carlos: EdUFScar, 2006.

Organização para a Cooperação e Desenvolvimento Econômico. Professores são importantes: atraindo, desenvolvendo e retendo professores eficazes. Organização para Cooperação e Desenvolvimento Econômicos. São Paulo: Editora Moderna, 2006.

REALI, Aline M.M.R.; TANCREDI, Regina M.S.P. \& MIZUKAMI, Maria da Graça N. Programa de Mentoria online: espaço para o desenvolvimento profissional de professoras iniciantes e experientes. Educação e Pesquisa, São Paulo, v. 34, n.1, p. 077-095, jan./abr. 2008.

ROSSI, J.R.D \& SILVA, M. J. Alfabetização e Matemática: a experiência de Sobral- CE, 2008. Free ebook. ESFAPEM. Disponível em: Ww.sbem.com.br/files/x_enem/relato_de_experiência/trabalhos.

VAILlANT, Denise. A profissão docente. In: SCHWARTZMAN, S.; COX, C. Políticas educacionais e coesão social: uma agenda latino-americana. São Paulo: iFHC, 2009. 
VAILLANT, Denise \& MARCELO, Carlos. Ensinando a ensinar: as quatro etapas de uma aprendizagem. Curitiba: Ed. UTFPR, 2012.

VIEIRA, Sofia L. Gestão e sucesso escolar: um enigma a decifrar. Relatório de pesquisa. Bolsa de Produtividade PQ/. CNPq - mar. 2008/fev. 2011. Fortaleza, 2011.

\section{Vídeos:}

Instituto Ayrton Senna. Sobral colhe os frutos após investimento pesado em educação. Disponível em: http:/www.youtube.com/watch?v=kU5q4rPwWeY.Recuperado em: $21 / 11 / 2012$

OCDE. Desempenho consistente e reformas bem-sucedidas na educação brasileira. (2011). Disponível em: http://portal.mec.gov.br/index.php?option=com_content\&view=article\&id=16838. Recuperado em: 21/11/2012. 